\title{
AUDIT OF MANAGEMENT OF ADULT CHOLEDOCHAL CYSTS
}

\author{
Ammad Ud Din Nasir, Muhammad Shoaib Khan, Anas Bin Saif*, Qasim Butt, Hanif Abbasi \\ Pak Emirates Military Hospital/National University of Medical Sciences (NUMS) Rawalpindi Pakistan, *FTC Kotli Pakistan
}

\begin{abstract}
Objective: To analyze the complexity and diversity of type, surgical management and complications in adult choledochal cysts presenting to a Hepatobiliary unit of a tertiary care hospital.

Study Design: Case series.

Place and Duration of Study: Pak Emirates Military Hospital Rawalpindi, from Jan 2017 to Dec 2019.

Methodology: All the patients diagnosed with choledochal cyst and underwent surgical procedure between Jan 2017 to June 2019 were analyzed. The clinical features, types, operative procedure and outcomes of the patients in terms of post-operative morbidity and mortality were assessed. Calvin Dindo classification was used to assess complications.

Results: A total of 17 patients were studied, out of which, 13 were females $(76.5 \%)$ and 4 were males $(23.5 \%)$ with mean age of $37.41 \pm 16.96$ years. There were 13 type I (76.5\%), 2 type IVa (11.8\%) and 1 type II (5.9\%) choledochal cysts according to Todani's classification. Extrahepatic cyst excision with a Roux-en-Y hepatico-jejunostomy was performed on all 17 patients. There was no mortality in the series. Post-operative complications occurred in 4 (23.5\%) patients, 2 were grade II, 1 was grade I and 1 grade III according to Clavin Dindo scale. Long-term follow up revealed recurrent cholangitis in 3 (17.6\%) patients which settled on antibiotic regime. The median follow up time was 1.5 years.

Conclusion: The total extra-hepatic excision with Roux-en-Y hepaticojejunostomy is the treatment of choice for adult choledochal cyst. The procedure has low morbidity and very low mortality.
\end{abstract}

Keywords: Choledochal cyst, Hepatobiliary disease, Obstructive jaundice.

How to Cite This Article: Nasir AUD, Khan MS, Saif AB, Butt Q, Abbasi H. Audit of Management of Adult Choledochal Cysts. Pak Armed Forces Med J 2021; 71(6): 1997-2000. Doi: https://doi.org/10.51253/pafmj.v6i6.4476

This is an Open Access article distributed under the terms of the Creative Commons Attribution License (https://creativecommons.org/licenses/by-nc/4.0/), which permits unrestricted use, distribution, and reproduction in any medium, provided the original work is properly cited.

\section{INTRODUCTION}

Choledochal cyst is a cystic dilatation of the biliary system. It is among the rarest congenital anomalies and is estimated to be present in 1 in 13,000 to 1 in 2 million live births. ${ }^{1}$ Although it is considered to be common in children, yet $25 \%$ of choledochal cysts present later in life..$^{2-4}$ In adults, it is often associated with complications making the diagnosis and subsequent treatment more difficult. ${ }^{5}$ Todani1 and his colleagues devised a method for classifying choledochal into five subtypes, which is widely accepted. The most common type is Type-I that is fusiform dilatation of common bile duct. ${ }^{6}$

Choledochal cyst is more common in Asian population with about half of the reported cases are from Japan. ${ }^{4}$ It is four times more common in female population. ${ }^{7}$ The classical triad of pain right hypochondrium, upper abdomen mass and jaundice is present in only a third of adult patients. The most dreadful complication of choledochal cyst is development of cholangiocarcinoma and the risk increases with age. Other

Correspondence: Dr Anas Bin Saif, House No. 10, Street no. 14, Sector G, DHA Phase-II, Islamabad Pakistan

Received: 13 Jun 2020; revision received: 26 Nov 2020; accepted: 01 Dec 2020 complications include cholangitis, pancreatitis and choledocholithiasis. Ultrasonography is the first line investigation modality to see the biliary tree with sensitivity of $71-97 \%$ in diagnosing choledochal cyst. Computed tomography is performed to delineate the intra and extra-hepatic anatomy and evaluate the surrounding relationships of cyst. The gold standard for diagnosing choledochal cyst is Magnetic Resonant Cholangio Pancreatography (MRCP) with sensitivity of 90$100 \%{ }^{8}$

Initially choledochal cysts were treated by drainage procedures (cysto-jejunostomy, cystodudenostomy) but they have been abandoned due to high complication rates and stricture formation. ${ }^{4}$ Currently complete excision of the cyst with Roux-en-Y hepatico jejunostomy is the recommended treatment of choice. ${ }^{9}$ It is pertinent to mention that complete excision of cyst does not abolish risk of carcinoma completely. ${ }^{10}$

The rationale of this study was to analyze the presentation and types of choledochal cysts in adult Pakistani population, demographic distribution, radiological and laboratory investigations and to evaluate the type of surgical procedures done and compare short and long-term outcomes in terms of morbidity and mortality. 


\section{METHODOLOGY}

This case series was conducted at Pak Emirates Military Hospital Rawalpindi after approval of Ethical Committee (ltr no. A/28/1), from January 2017 to June 2019. Sample size was calculated by WHO sample size calculator keeping the confidence interval of $95 \%$ and prevalence of choledochal cyst to $0.1 \% .^{1}$ The data was collected by non-probability convenient sampling technique.

Inclusion Criteria: All the patients with age more than 18 years with characteristic symptoms, signs and radiological confirmed diagnosis of choledochal cyst were included in the study.

Exclusion Criteria: Patients with other causes of obstructive jaundice, pain abdomen or with malignant disease were excluded from the study.

All the patients underwent ultrasonography and Magnetic Resonant Cholangio Pancreatography, while 2 patients also had CT scan to rule out suspected pathology other than choledochal cyst. A proforma was designed to including demographic features of the patients, initial signs and symptoms, relevant laboratory results, radiological studies, per-operative findings and post-operative recovery. Follow up was done up to maximum period of two years for post-operative morbidity. Analysis of various signs and symptoms, operative findings, co-morbidities and relevant investigations was done. Histological and radiological co-relation were also carried out to find out the particular type of choledochal cyst. The types of choledochal cysts, were assigned according to the classification of Todani et al. ${ }^{1}$ Calvin Dindo 2 classification was used to assess complications.

The demographic data was analyzed using Statistical Package for the Social Sciences (SPSS) version 21 and mean with standard deviation was calculated for age. Frequency and percentages were calculated for ordinal variables such as symptoms, signs and radiological findings.

\section{RESULTS}

There were 17 patients that were included in the study out of which 13 were females $(76.5 \%)$ and 4 were males $(23.5 \%)$. Age of patients ranged from $18-70$ years with mean age of $37.41 \pm 16.96$ years. Four $(23.5 \%)$ patients were over 50 years of age. Five $(29.4 \%)$ patients had some co-morbidity, out of which 3 (17.6\%) had diabetes mellitus and $2(11.8 \%)$ had more than one disease. The main complaint of patients was pain right hypochondrium present in $14(82.4 \%)$ patients followed by jaundice in 3 patient (17.6\%) while 2 patients had classical triade of fever jaundice and mass as shown in Figure.

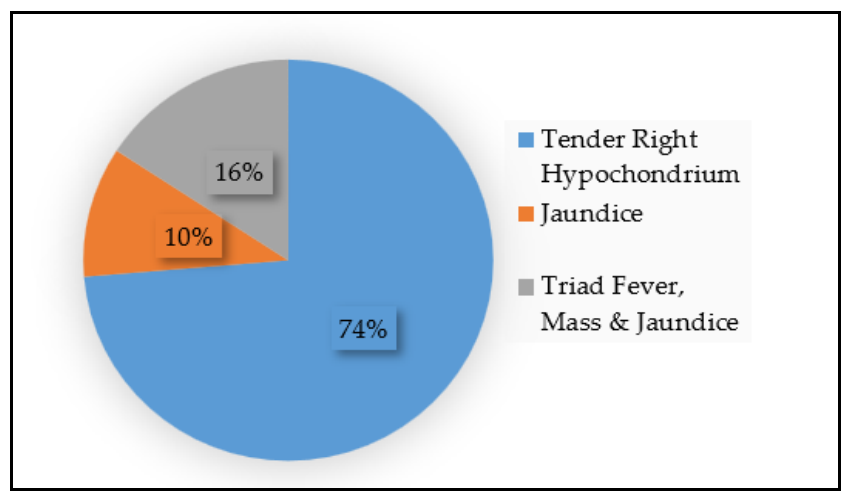

Figure: Frequency of signs associated with choledochal cysts $(\mathrm{n}=17)$.

Important positive abdominal examination findings included tenderness right hypochondrium in 14 cases $(82.4 \%)$, mass in upper abdomen in 3 patients $(17.6 \%)$. One $(5.9 \%)$ patient had previous cholecystectomy and one $(5.9 \%)$ had endoscopic retrograde cholangiopancreatography. There were deranged liver function tests in $5(29.4 \%)$ cases showing obstructive pattern (raised Alkaline Phosphatase and bilirubin). Three $(17.6 \%)$ patients had raised white cell count depicting presence of infection. Ultrasonography was performed in all cases followed by Magnetic Resonant Cholangio Pancreatography (MRCP) which diagnosed choledochal cyst accurately. The final diagnosis of choledochal cyst was made per-operatively and on histopathological report of specimen. Follow-up data was obtained via a review of patients' medical records and through follow-up visits. Histopathological confirmation of the diagnosis was obtained in all cases. There was type I choledochal cyst in $13(76.5 \%)$ cases, whereas type IVa cyst was present in 3 cases $(17.6 \%)$ and one $(5.9 \%)$ case had type II cyst. Fifteen (88.2\%) patients had some sort of complication of choledochal cyst, 4 had stone in common bile duct, 4 had cholangitis and 5 had obstructive pattern of liver enzymes while 1 had stricture in distal part and 1 patient had repeated bouts of pancreatitis as shown in Table-I.

Table-I: Complications associated with choledochal cysts in adults $(\mathbf{n = 1 7 )}$.

\begin{tabular}{l|c}
\hline Complications & n (\%) \\
\hline Biliary-lithiasis & $4(23.5)$ \\
\hline Cholangitis & $4(23.5)$ \\
\hline Stricture & $1(5.9)$ \\
\hline Pancreatitis & $1(5.9)$ \\
\hline
\end{tabular}


All patients underwent excision of common bile duct and Roux-en-Y Hepatico-jejunostomy after optimization. 5/0, and 4/0 PDS was used t-enteroentrostomy was done about $60 \mathrm{~cm}$ below the loop with $3 / 0$ PDS continuous. There was no mortality. However 4 patients $(23.5 \%)$ developed postoperative complications. Two patients $(11.8 \%)$ developed bile leaks and one patient $(5.9 \%)$ had basal atelectasis while one had seroma (5.9\%). These have been classified according to Calvin dindo 2 classification in Table-II. The median postoperative length of hospital stay was 8 days (range 6-12 days).
Abdominal Ultrasound and CT scan usually delineate the cyst. There could be an atypical pancreatic-biliary union; such anomalous junctions can be delineated by $\mathrm{ERCP}^{21}$. In present study, ERCP was done in only one patient $\mathrm{du}$ before referral to our center. We did not do ERCP in any of our patients it can lead to severe pancreatitis in patients with choledochal cyst.

Choledochal cyst can be associated with pancreatitis as seen in one of our patients. ${ }^{16}$ The commonest type of cyst was type 1 which has also been confirmed in other studies. ${ }^{22}$ A rather dreadful and wellrecognized complication of choledochal cyst is the

Table-II: Types of post-operative complications according to clavin dindo grades $(n=4)$.

\begin{tabular}{c|c|c|c|c|c|c}
\hline Patient No. & Type of Cyst & Age(years) & Gender & Complication & Clavin Dindo Scale & Management \\
\hline 1 & Type I & 50 & Female & Minor leak & Grade II & Conservative \\
\hline 2 & Type IVa & 47 & Male & Major leak & Grade III & Redo-anastamosos \\
\hline 3 & Type I & 65 & Female & Basal atelectasis & Grdae II & Conservative \\
\hline 4 & Type I & 38 & Female & Seroma & Grade I & Conservative \\
\hline
\end{tabular}

\section{DISCUSSION}

The exact cause of choledochal cyst is not known. One explanation can be due to the abnormal pancreatobiliary junction (APBJ) which causes backlash of pancreatic juice into the common bile duct (CBD). This anomaly is frequently encountered in choledochal cyst. ${ }^{11-13}$

Adult Choledochal cysts mostly present with complicated clinical and pathological features that alter surgical management as seen in study by Nagoney et $a l,{ }^{14}$ this complex presentation also seen in present study. Similarly, most choledochal cysts occur in women, also seen in present study with $76.5 \%$ patients being females in our study. This high incidence in female population was also seen in studies of Hewitt et al, Stain et al.16-19 The present study also confirms that adult choledochal cyst patients usually have vague signs and symptoms. The most common clinical presentation of adults with choledochal cyst was non-specific abdominal pain in $82.4 \%$ of our patients followed by cholangitis and jaundice similar to previous studies reporting nonspecific abdominal pain occurring in $70 \%$ of patients. ${ }^{16-19}$ A palpable mass is uncommon as observed by $\mathrm{O}^{\prime} \mathrm{Neil}$ in his study 20 , similarly in present study, only 3 patients with palpable mass.

The symptoms of choledochal cyst are sometimes indistinguishable from those of biliary calculus diseases. In adults, the choledochal cyst is present alongside some other hepatobiliary conditions (e.g. biliary lithiasis pancreatitis and malignant disease) resulting in requirement of an individualized therapeutic approach. development of cancer namely cholangiocarcinoma. It is pre-sumed to develop in patients who went undiagnosed. Similarly, tumor is also seen to form in a cyst that was mistreated by cyst enterostomy. The incidence of carci-noma in choledochal cyst ranges from 2.5$15.6 \% .{ }^{23}$ However, in our series none of the patient had malignancy on histopathology. This absence of malignancy is histopathology specimen was also observed in other studies.22 The treatment of cancer developing due to choledochal cyst merits radical excision of the biliary tract as the disease is not limited to the cyst. The cancer can be present in other areas of hepatobiliary system such as the gallbladder, pancreas and liver. ${ }^{24-25}$

The gold standard treatment recommended by most centers around the world is total extrahepatic cyst excision with Roux en-Y hepaticojejunostomy. ${ }^{21}$ In our study, same procedure was adopted, 4/0 PDS was used for the anastomosis, like in other studies. ${ }^{22}$ Cystoenterostomy is no longer recommended. Like other studies, we also found that hepaticojejunostomy is not only safe but also prevents morbid issues as residual cyst, bile stasis, recurrent cholangitis, formation of denovo stone, pancreatitis and carcinoma of bile duct. $16,17,19$ It is also recommended that adults diagnosed on screening or incidental must undergo complete excision. ${ }^{25}$ In this series, $3(17.6 \%)$ out of 17 patients with type I cysts who had undergone a hepaticojejunostomy developed cholangitis. This result is comparable to overall literature which quotes incidence of $18 \%$ postoperative cholangitis if the recommended surgery is undertaken in a specialized hepatobiliary unit. ${ }^{22}$ 


\section{CONCLUSION}

After experience of surgical management of 17 patients, we can safely conclude that adult choledochal cyst should be treated by total extrahepatic cyst excision and this is a safe procedure with low morbidity and mortality. However, cases are best managed in a specialized tertiary surgical units for satisfactory post-operative outcome.

\section{Conflict of Interest: None.}

\section{Authors' Contribution}

AUDN: Data collection, data analysis, MSK: Data collection, ABS: Data collection, analysis, QB: Supervisor, HA: Data analysis.

\section{REFERENCES}

1. Todani T, Watanabe Y, Narusue M, Tabuchi K, Okajima K. Congenital bile duct cysts classification, operative procedures and review of thirtyseven cases including cancer arising from choledochal cyst. Am J Surg 1977; 134(1): 263-269.

2. Dindo D, Demartines N. Classification of surgical complications: a new proposal with evaluation in a cohort of 6336 patients and results of a survey. Ann Surg 2004; 240(2): 205-213.

3. Fan F, Xu DP, Xiong ZX, Li HJ, Xin HB, Zhao H, et al. Clinical significance of intrapancreatic choledochal cyst excision in surgical management of type I choledochal cyst. J Int Med Res 2018; 46(3): 1221-1229.

4. Roy AK, Bhat SK, Bhushan R, Ansari NA, Mishra PK, Ahmad M, et al. Experiences of choledochal cyst in pediatric and adult population: A case series. Saud Surg J 2019; 7(4): 138.

5. Katabathina VS, Kapalczynski W, Dasyam AK, Anaya-Baez V, Menias CO. Adult choledochal cysts: current update on classification, pathogenesis, and cross-sectional imaging findings. Abdominal Imag 2015; 40(6): 1971-1981.

6. Xia HT, Yang T, Liang B, Zeng JP, Dong JH. Treatment and outcomes of adults with remnant intrapancreatic choledochal cysts. Surg 2016; 159(2): 418-425.

7. Nazir Z. Choledochal Cyst-A Different disease in newborns and infants. J Coll Physicians Surg Pak 2014; 24 (11): 868-870.

8. Khandwala K, Sajjad N, Afzal S. Radiological manifestations of choledochal cysts: a pictorial review. Pak J Radiol 2017; 27(4): 1-4.

9. Lisboa M, Salizi J, Queiroz J, Nobre IM, Castro ILA, Cardoso MAS, et al. Reoperation for the treatment of choledochal cyst in adults. Rev Med Minas Gerais 2015; 25(1): 128-131.
10. Shah NA, Hadi A, Mehreen T, Kalim M, Hussain M, Shah I, et al. Clinical presentation and management of adult choledochal cyst: A retrospective review. J Postgrad Med Inst 2017; 31(1): 51-55.

11. Ronnekleiv-Kelly SM, Soares KC, Ejaz A, Pawlik TM. Management of choledochal cysts. Curr Opin Gastroenterol 2016; 32(3): 225-231.

12. Yeung F, Fung AC, Chung PH, Wong KK. Short-term and longterm outcomes after Roux-en-Y hepaticojejunostomy versus hepaticoduodenostomy following laparoscopic excision of choledochal cyst in children. Surg Endoscop 2019; 1(1): 1-6.

13. Thambi-Dorai CR, Visvanathan R, McAll GL. Type IVa choledochal cysts: surgical management and literature review. Aust N Z J Surg 1991; 61(7): 505-510.

14. Nagoney DM, Mcllrath DC, Adson MA. Choledochal cysts in adults: Clinical management. Surgery 1984; 96(4): 656-663.

15. Rossi RL, Munson JL, Braasch JW, Silverman ML. Management of bile duct cysts in adults. Arch Surg 1986; 121(1): 410-415.

16. Hewitt PM, Krige JE, Bornman PC, Terblanche J. Choledochal cysts in adults. Br J Surg 1995; 82(1): 328-385.

17. Stain SC, Guthrie CR, Yellin AE, Donovan AJ. Choledochal cyst in the adult. Ann Surg 1995; 222(1): 128-133.

18. Chen HM, Jan YY, Chen MF, Wang CS, Jeng LB, Hwang TL, et al. Surgical treatment of choledochal cyst in adults: results and long-term follow-up. Hepatogast 1996; 43(1): 1492-1499.

19. Lenriot JP, Gigot JF, Segol P, Fagniez PL, Fingerhut A, Adloff M. Bile duct cysts in adults: a multiinstitutional retrospective study. Ann Surg 1998; 228(1): 159-616.

20. O'Neil J. Choledochal cyst. Curr Prob Surg 1992: 1(1): 369-410.

21. Chijiwa K, Koga A. Surgical management and long-term followup of patients with choledochal cysts. Am J Surg 1993; 165(1): 238-242.

22. Xia HT, Liu Y, Yang T, Liang B, Wang J, Dong JH. Better longterm outcomes with hilar ductoplasty and a side-to-side Rouxen-Y hepaticojejunostomy. J Surg Res 2017; 215(1): 21-27.

23. Friedmacher F, Ford KE, Davenport M. Choledochal malformations: global research, scientific advances and key controversies. Pediatr Surg Int 2019; 35(3): 273-282.

24. Ishibashi T, Kasahara K, Yasuda Y, Nagai H, Makino S, Kanazawa $\mathrm{K}$. Malignant change in the biliary tract after excision of choledochal cyst. Br J Surg 1997; 84(1): 1687-191.

25. Mukai M, Kaji T, Masuya R, Yamada K, Sugita K, Moriguchi T, et al. Long-term outcomes of surgery for choledochal cysts: a single-institution study focusing on follow-up and late complications. Surgery Today 2018; 48(9): 835-840. 